\title{
Modeling population dynamics and economic growth as competing species: An application to $\mathrm{CO}_{2}$ global emissions
}

\author{
SALVADOR ENRIQUE PULIAFITO* \\ Universidad Tecnológica Nacional (Facultad Regional Mendoza y Buenos Aires) \\ JosÉ LUIS PULIAFITO \\ Universidad de Mendoza \\ MARIANA CONTE GRAND \\ Universidad del CEMA
}

Since the beginning of the last century the world is experiencing an important demographic transition, which will probably impact on economic growth. Many demographers and social scientists are trying to understand the key drivers of such transition as well as its profound implications. A correct understanding will help to predict other important trends of the world primary energy demand and the carbon emission to the atmosphere, which may be leading to an important climate change. This paper proposes a set of coupled differential equations to describe the changes of population, gross domestic product, primary energy consumption and carbon emissions, modeled as competing-species as in Lokta-Volterra prey-predator relations. The predator-prey model is well known in the biological, ecological and environmental literature and has also been applied successfully in other fields. This model proposes a new and simple conceptual explanation of the interactions and feedbacks among the principal driving forces leading to the present transition. The estimated results for the temporal evolution of world population, gross domestic product, primary energy consumption and carbon emissions are calculated from year 1850 to year 2150. The calculated scenarios are in good agreement with common world data and projections for the next 100 years.

Keywords: Population dynamics, economic growth, primary energy consumption, carbon emission model, Lokta-Volterra Equations, Prey-predator model.

\footnotetext{
* Correspondence should be addressed to: epuliafito@ frm.utn.edu.ar. The views and opinions expressed in this publication are those of the authors and are not necessarily those of the Universidad del CEMA.
} 


\section{Introduction}

Since the last century, the world has experienced important changes in demographic parameters. Better health care and social improvements have decreased infant mortality and have expanded longevity. As a consequence, world population had increased constantly since 1800 up to approximate 1970, but more recently that annual growth rate has been declining at a high pace, showing a visible demographic transition. This transition presents several aspects, on one side population growth is slowing, but also age structure of the population is changing, decreasing young people and rising the elderly proportion of the population. Moreover, in developed countries, increasing longevity and migration has masked an important reduction trend in fertility. Different countries and regions show different stages of this demographic transition. Many developing countries in East and Southeast Asia and Central and Eastern Europe will experience significant aging from about 2020. In other developing countries, however, the demographic transition is less advanced, and working-age populations will increase in the coming decades (IMF, 2004). The question on how to model the population changes has motivated demographers and social scientists to find suitable models and new ideas. This demographic transition will most probably have a real impact on economic growth, and therefore, the development of sound models will be increasingly relevant. Moreover, these changes will also impact on energy primary consumption and carbon emissions, a very sensitive aspect in dealing with global climatic change.

Economic growth has been a major concern among economic theorists for centuries. Despite the different views, population growth has always played an important role. But, while some view population as detrimental to economic growth, others see population as a major contributor. ${ }^{1}$ The first type of ideas goes back to the writings of Thomas Malthus (Malthus, 1798). The reasoning was that since land is limited and has diminishing marginal returns to its use, as population increases and the land is harvested more intensely, the economy reaches a zero growth in per capita GDP. Similarly, though moving away from fixed land to the possibility of reproducible capital goods, Robert Solow (Solow, 1956) came to the conclusion that increasing population produces a slowing economy, since more investment is needed to maintain the same per capita output. This happens because, when the ratio of machines per worker increases, per capita output increases as well, each time by diminishing incremental amounts. Hence, at some point, the growth rate of GDP per capita ends up falling

\footnotetext{
${ }^{1}$ For a detailed review of the literature of the determinants of economic growth, see Barro and X. Sala-I-Martin (1998).
} 
to zero. The "solution" to this trap, brought about by the neoclassical economic growth literature, was to assume that the economy grew through an exogenous technical progress (see, for example, the Cass-Koopmans-Ramsey model, from Ramsey 1928, Cass 1965 and Koopmans 1965). The role of technological changes in population and economic growth has also been highlighted in several studies (Schumpeter, 1934; Kremer, 1993; and Kozulj, 2003).

But it should also be considered that population growth has two effects: it increases the number of consumers and at the same time increases the number of workers devoted to productive activity and research, as well as the scale of the economy. Hence, the so-called "endogenous growth models" (lead by Paul Romer and Robert Lucas in the early 80s) were able to forecast growth of GDP based, not on exogenous technical progress, but rather on the existence of investment on research and development or other sorts of externalities that generate by themselves growth (Romer, 1986; Lucas, 1988; and a review of their research in Romer, 1994). Hence, a larger population means more chance of having that kind of effect. The economic theory debate on whether population growth is detrimental or beneficial to the welfare of humanity essentially comes down to the opposing conclusions of the exogenous versus the endogenous growth models, or in another words, diminishing returns versus creation of technology to overcome them. Empirically, the definition of economic growth as an increase in output per capita implies an inverse relationship between output (GDP) and population, but not necessarily as a cause-effect relationship; if population causes total economical output to increase faster than population does, then it will produce an increase in per capita output. In fact, data evidence does not unambiguously support either view of population growth. In any of the discussed approaches, it is clear that there is a strong interaction between population and economic output.

In this paper, the population dynamics and economic growth are treated as a dynamic system described by a set of ordinary differential equations in a general form of competing species. The typical predator-prey model or Lotka-Volterra relation (Lokta, 1925 and Volterra, 1926), is well known in the biological, ecological and environmental literature (Carpenter et al., 1994; Janssen et al., 1997; Jost and Arditi, 2000; Jost and Ellner, 2000; Shertzer et al., 2002; Beisner et al., 2003, Song and Xiang, 2006, and many others). These relations have even been applied in other fields, for example, in atmospheric chemistry (Wang et al, 2002), in urban growth studies (Capello and Faggian, 2002, Dendrinos and Mullally 1981, 1983; Puliafito, 2002, 2004, 2006), in the tourist industry (e.g. Casagrandi and Rinaldi, 2002; Hernández and León, 2006). Economic models based on prey-predator relations and system dynamics are used to study the complex feedbacks between economy, population, 
labor and capital (Goodwin, 1969; and Samuelson, 1971; Woodwell, 1998; Johansen and Sornette, 2001; Ramos-Gilberto, 2005; Krutilla and Reuveny, 2006, Forrester, 1961, 1971).

In parallel to the above discussion of the links between population, GDP and technological change, there is an equally large literature on what are the determinants of world emissions. The environmental economics literature on this issue has two distinct lines of research. A theoretical one, including pollution in mathematical growth models and an empirical one, based mostly on different equations specifications relating mainly carbon emissions to GDP per capita. ${ }^{2}$ The theoretical works analyze the difference between optimum and equilibrium and the possible solutions to that gap (standards, taxes, etc.), including modeling of several countries, but with few data counterpart. On the other side, the emissionsgrowth debate in the empirical articles is usually referred to as Environmental Kuznets Curve (EKC), since it reflects that there is an inverted- $U$ relationship between emissions and GDP per capita. ${ }^{3}$ The intuition of that shape is that at low levels of growth, the impact on the environment is limited. Then, as development takes-off, resource depletion and waste generation accelerates, while at higher levels of income, increased demand for environmental quality results in a decline of environmental degradation. For the specific case of carbon emissions, studies as Holtz-Eakin and Selden (1995), Schmalensee et al (1998) obtained such a result. The rest of the determinants of carbon emissions (for example, population and technology) are usually incorporated in the econometric regressions as "control" in a linear way. For example, Shi (2003) introduced a linear population term, while Neumayer (2002) included a technology variable, both of which showed a significant relation with environmental degradation. However, when more flexible functional forms are allowed a more complex relationship between carbon emissions and population, and carbon emissions and technology emerges. For example, in that line, Lantz and Feng (2006) found that population and technology exhibit an inverted U-shaped and U-shaped relationship respectively with $\mathrm{CO}_{2}$ emissions.

More on the side of ecological economics literature, during the early 1970s, Ehrlich, Holdren and Commoner proposed the IPAT identity as a first guess to analyze the driving forces of environmental change, i.e., Commoner et al. (1971); Ehrlich and Holdren (1972). The IPAT calculations establish that environmental impacts are the product or combination of three main driving forces: population, affluence (per capita consumption or production) and technology (impact per unit of consumption or production). IPAT has been widely used to

\footnotetext{
${ }^{2}$ For a review of the literature on economic growth and the environment, see Panayotou (2000).
} 
study the effects of human activities on the environment (Stern et al., 1992; Harrison and Pearce, 2000, Harrison, 1993; Raskin, 1995; York et al., 2002). Here, following that same idea, carbon emissions and energy demand are modeled as dependent on socio-economic variables.

This paper is organized in the following way. In Section 2, we propose a model for population and economic growth, and we simulate it from year 1850 to year 2150. The results of the simulation studies are then compared to data and estimations of International Agencies. In Section 3, we introduce to the same model a new set of equations to estimate the world primary energy consumption and carbon emissions. The results are compared to world agencies estimations as the IPCC Scenarios. We discuss in Section 4 the sensitivity of the model and conclude in Section 5.

\section{Model and Simulations for Population and GDP Dynamics}

\subsection{The Model}

Lokta and Volterra (Lokta, 1925; Volterra, 1926) first proposed a relation to explain the dynamics of two (or more species), known also as prey-predator equations. Lokta Volterra relations (LVR) might be seen as a particularization of more general system dynamics equations. In fact, the LVR can be found in the literature in many different forms and variations, but it may be written as a set of two (or more) ordinary differential equations (ODE). ${ }^{4}$ Some authors explicitly incorporate a logistic growth function for one of the species (MacArthur, 1970, Armstrong and MacGhee, 1980, Abrams and Holt, 2002; Marchetti et al, 1996, Seidl and Tisdell, 1999). Some other LVR equations, especially in ecology, explicitly specifies a functional response to describe the interaction between the two species (i.e., Holling, 1959; Blaine, and De Angelis, 1997; Fenlon and Faddy, 2006; among others). Some LVR also include the concept of carrying capacity of the environment (e.g. Seidl and Tisdell, 1999). ${ }^{5}$ For many years, social scientists and demographers have used the concept of logistic growth to describe population dynamics. Moreover, defining a carrying capacity implies the idea of an upper limit to that logistic growth.

\footnotetext{
${ }^{3}$ In fact, Kuznets (1965) original work estimates the linkages between income and inequality.

${ }^{4}$ Interesting to note is the fact that, depending on the chosen parameters, these coupled no linear relation may show a chaotic behavior.

${ }^{5}$ These authors present a deep analysis on the various concepts related to logistic growth and carrying capacity especially applied to human demography studies as environmental limits to human activity. They also suggest
} 
The LVR, in essence, describes the interaction of two species, where the growth rate of the first specie is dependent on the growth rate of the other species. In a very general way, these equations are expressed as:

$$
\left\{\begin{array}{l}
\frac{d p}{d t}=a p-r p g \\
\frac{d g}{d t}=r p g-b g
\end{array}\right.
$$

where $p$ is the population of one specie (i.e. the prey), $g$ the population of the second specie (i.e. the predator), $\frac{d p}{d t}$ and $\frac{d g}{d t}$ are the annual changes. The product rpg is the interaction between both species, which represents a control or limiting mechanism, being $r$ a coefficient that regulates such interaction. The coefficient $a$ represents the prey's population growth rate in absence of any interaction with the predator, and $b$ is the annual death rate of the second specie in absence of the first specie.

From a mathematical point of view, if $p$ and $g$ have similar temporal variation, which corresponds to a stationary frame, the ratio $g / p$ can be approximated to a constant $(\approx q)$. Then, it is possible to rearrange Equation (1) and show that $p$ and $g$ will produce two logistic type equations for $p$ and $g$ :

$$
\text { if } g / p \approx \text { constant } \rightarrow\left\{\begin{array}{l}
\frac{d p}{d t}=a p-r p g \approx a p-r q p^{2} \\
\frac{d g}{d t}=r p g-b g \approx \frac{r}{q} g^{2}-b g
\end{array}\right.
$$

However, if the ratio $g / p$ is not constant, a logistic type curve can only result if also $a$ and $b$ are not constant but have a proper variation. To represent these types of non stationary frames adequately, in particular in what concerns the short-run changes, equation (2) can be modified by including an additional function $f(p, g, t)$, which modulates the growth rate $a$ and $b$. Function $f(p, g, t)$ might be interpreted as an external excitation function, which comprises all other causes of variation not included in the predator-prey solely mechanism.

caution in the use of this concept in human ecology, not to be interpreted as universal constant but continuously modified by social and institutional settings. 
In fact, the LVR is a closed model because the eventual changes in the carrying capacity of the substrate are not explicit. To make them explicit, considering now an open model, the substrate has to be taken as varying along time, for example due to the changing culture and technology. Although population and gross domestic product may be fitted to logistic type curves, there is no clear indication on which may be the value of the maximum carrying capacity value, nor a clear explanation for this limitation process. One possible feedback mechanism, which may explain this limitation processes is linked to the availability of natural resources. Indeed, the idea of an upper population limit can be associated to the availability of resources. ${ }^{6}$

Here, the proposed set of equations is a generalization in the form of an open-system dynamic model. Note that the rates of production or consumption of the species are written without specifying the signs. To capture the influence of the variation of the substrate on the growth rates of the considered species, we include a functional response $f$. Now Equation (1) may be rewritten as:

$$
\left\{\begin{array}{l}
\frac{d p}{d t}=\left(\alpha_{1}+\alpha_{3} f\right) p+\alpha_{2} g p \\
\frac{d g}{d t}=\beta_{1} g+\beta_{2} p g
\end{array}\right.
$$

where the coefficients, $a, b$ and $r$, have been replaced (to include their own signs and units) by $\alpha_{1}, \alpha_{2}$ and $\beta_{1}, \beta_{2}$, while $\alpha_{3} f$ modulates the growth rate $\alpha_{1}$.

When applying biological and ecological analogies, such as LVR, to other sciences, one is tempted to define one variable as a prey and the other as the predator. For example, Dendrinos and Mullally $(1981,1983)$ proposed an application of LVR to urban dynamics, defining the urban population as the predator, and per-capita income as the prey. Instead also for a similar urban dynamics application, Cappello and Faggian (2002) define population as the prey, and land price as the predator. So, in this respect, we prefer to apply a general system dynamic approach without specifically naming either variable as prey or predator, since we could probably find different intuitive justification to choose one or the other option. However, as it will be shown below, the GDP (as proxy for natural resources) could be interpreted as the prey and the population as the predator. Initially an increasing growth rate of the GDP favors an increase in the population, up to certain population level, where it

\footnotetext{
${ }^{6}$ An interesting critical review of ecological and economical analogies is presented by Ayres (2004).
} 
follows first a population decline followed later by a GDP reduction, beginning a new cycle or transition.

The experience shows that most positive culture and technology changes arise in scenarios with an increasing $g / p$ rate. Therefore, the function $f(g, p, t)$ could be expressed in terms of the quotient $g / p$ or more generically as an expansion in power series of the type $\Sigma$ $k_{n .}(g / p)^{n}$, with $n$ being a positive integer. A first order approximation is to set $f$ equal to $k_{l}$ $(g / p)$, but other solutions are also possible adding further terms with greater values of $n$. If $f$ $=k \mathrm{~g} / \mathrm{p}$ is replaced in (3), equation (4) follows:

$$
\left\{\begin{array}{l}
\frac{d p}{d t}=\alpha_{1} p+\alpha_{3} k_{1} g+\alpha_{2} g p \\
\frac{d g}{d t}=\beta_{1} g+\beta_{2} p g
\end{array}\right.
$$

As can be seen in this equation, $\left(\alpha_{3} k_{1} g+\alpha_{2} g p\right)$ is proportional to $d g / d t$, which again clearly suggests the coupling between changes in population and changes in GDP.

The coefficients $\alpha_{1}$ and $\beta_{1}$ represent the growing rates for population and GDP; $\alpha_{2}$ and $\beta_{2}$ are the main control mechanism in the LVR, which moderates the growth in $p$ and $g$. Since $g / p$ has a near exponential growth, the first term in Equation (4), for example, with $k_{1}$ positive, will induce to produce a higher growth rate. Since $\alpha_{2}$ is negative, it will produce a reduction in the growth rate, specially for higher values of $g$. The combination of both coefficients allows a great flexibility in the dynamic of the variables.

\subsection{Simulations}

As mentioned above, the LVR type equations are characterized as ordinary differential equations ODE, whose solutions may derive in numerical instabilities (stiff equations). These instabilities may occur, for example, when the coefficients of the ODE are several orders of magnitude different. For an interesting discussion on stiff ODE see Wang et al (2002); Sepplet and Richter (2005); Press et al (1999). In this case, we solve the ODE using a Rosenbrock modification to Runge-Kutta-Fehlberg (RKF) method in a FORTRAN 77 code as suggested by Press et al (1999). As sources of data, for years 1960 to 2006; and projections

to 2015, we consulted several international agencies databased, such us the International Energy Outlook (EIA, 2005), United Nations Demographic Yearbook (2004), the US Census Bureau (2006), the World Bank World Development Indicators (2005), International 
Monetary Fund (IMF, 2004). For historical data (prior to 1960) we consulted estimations from United Nations (1973, 1999), McEvedy and Jones (1978), Biraben (1980), Durand (1974, 1977), Klein Goldewijk (2005), and Maddison (1995). Additionaly we compared the historical values used in several global model such as Dynamic Integrated Climate-Economy Model-DICE (Nordhaus, 1992), and Integrated Modeling of Global Climate Change-IMAGE (Alcamo, 1994).

Figure 1 shows the predicted values of world population and world gross domestic product from year 1850 to 2150 as calculated by equations (3). The values used in Figure 1 are as follow: initial values $T_{0}=1850$, final year $T_{F}=2100 ;$ step size $D_{T}=1.0 ; P_{0}=1.15$ Billions inhabitants; $G_{0}=0.21$ Trillions USS. The annual rates are $\alpha_{1}=0.3 \%, \alpha_{2}=-55 /\left(10^{18}\right.$ $\mathrm{U} \$ \mathrm{~S}) ; \alpha_{3} k_{1}=5.2 \mathrm{Hab}$. / U\$S, $\beta_{1}=3.1 \%, \beta_{2}=-2 /\left(10^{22}\right.$ Hab. $)$ Figure 2 compares annual world population changes for the model output with respect to the data and projections from international agencies. Figure 2A shows the population changes in percentage and Figure 2B as absolute changes in millions of inhabitants. Figure 3 shows the world annual changes in \%, calculated using the model and compared to international databases. It is interesting to note that the predicted shape of population over time follow a logistic type curve (Figure 1); and consequently the annual changes is a "bell-shaped" type curve (Figure 2 B) as suggested above in equation (2). ${ }^{7}$ By selecting a higher $\beta_{2}$ coefficient also the GDP will take a logistic type curve. Figure 4 shows the evolution of per capita GDP.

\footnotetext{
${ }^{7}$ The logistic function $\frac{d y}{d t}=b y-\frac{b}{a} y^{2}$, has a solution of the type $y=\frac{a}{1+k \exp (-b t)}$. Its derivative is a bell shaped function of the form $y^{\prime}=\frac{a k b \exp (-b t)}{(1+k \exp (-b t))^{2}}$, with $k$ and a being constants.
} 
Figure 1. Comparison Model and Data for world population and GDP

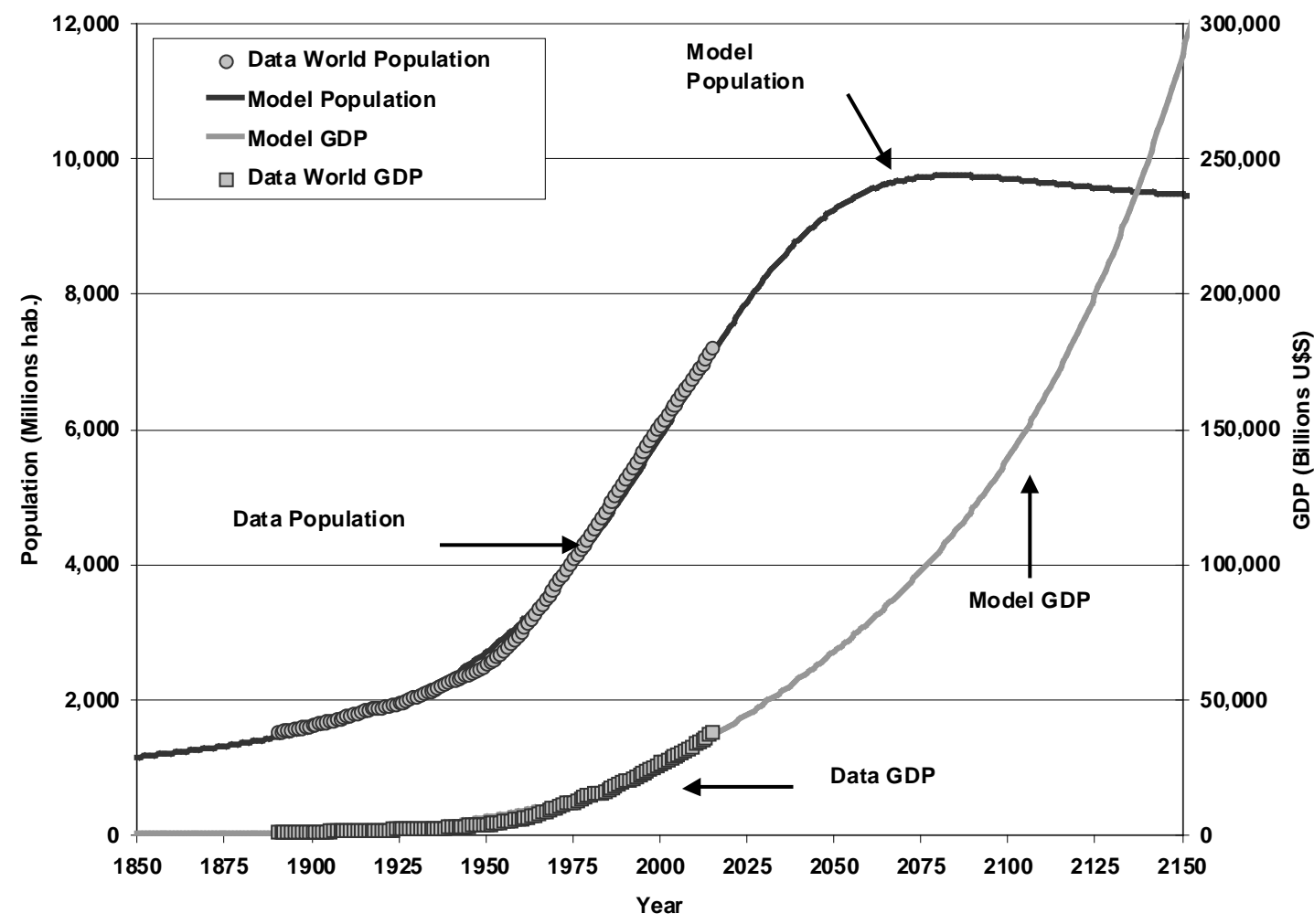

Figure 2A. Comparison Model and Data for annual world population changes (\%)

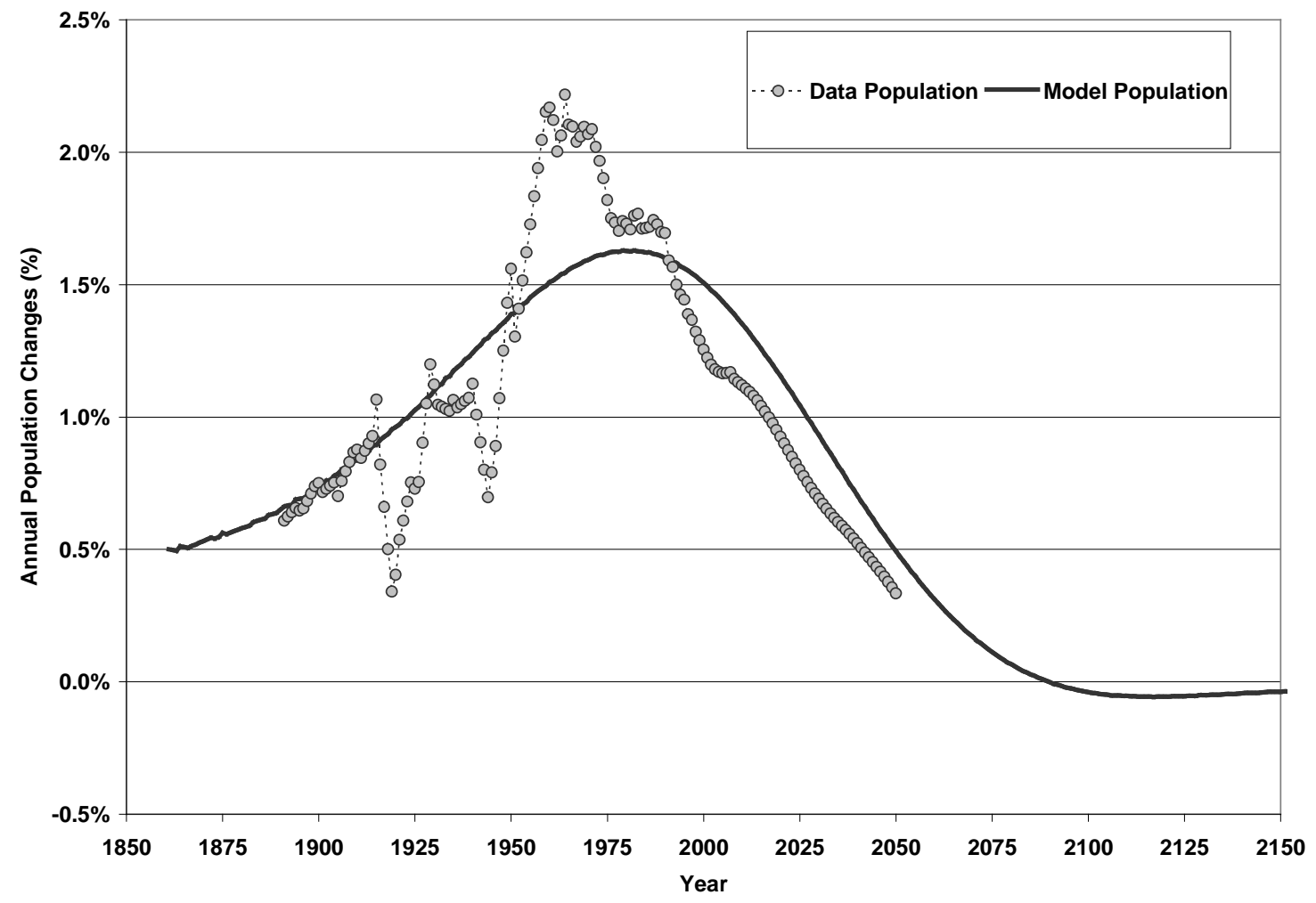


Figure 2B. Comparison Model and Data for annual world population absolute changes

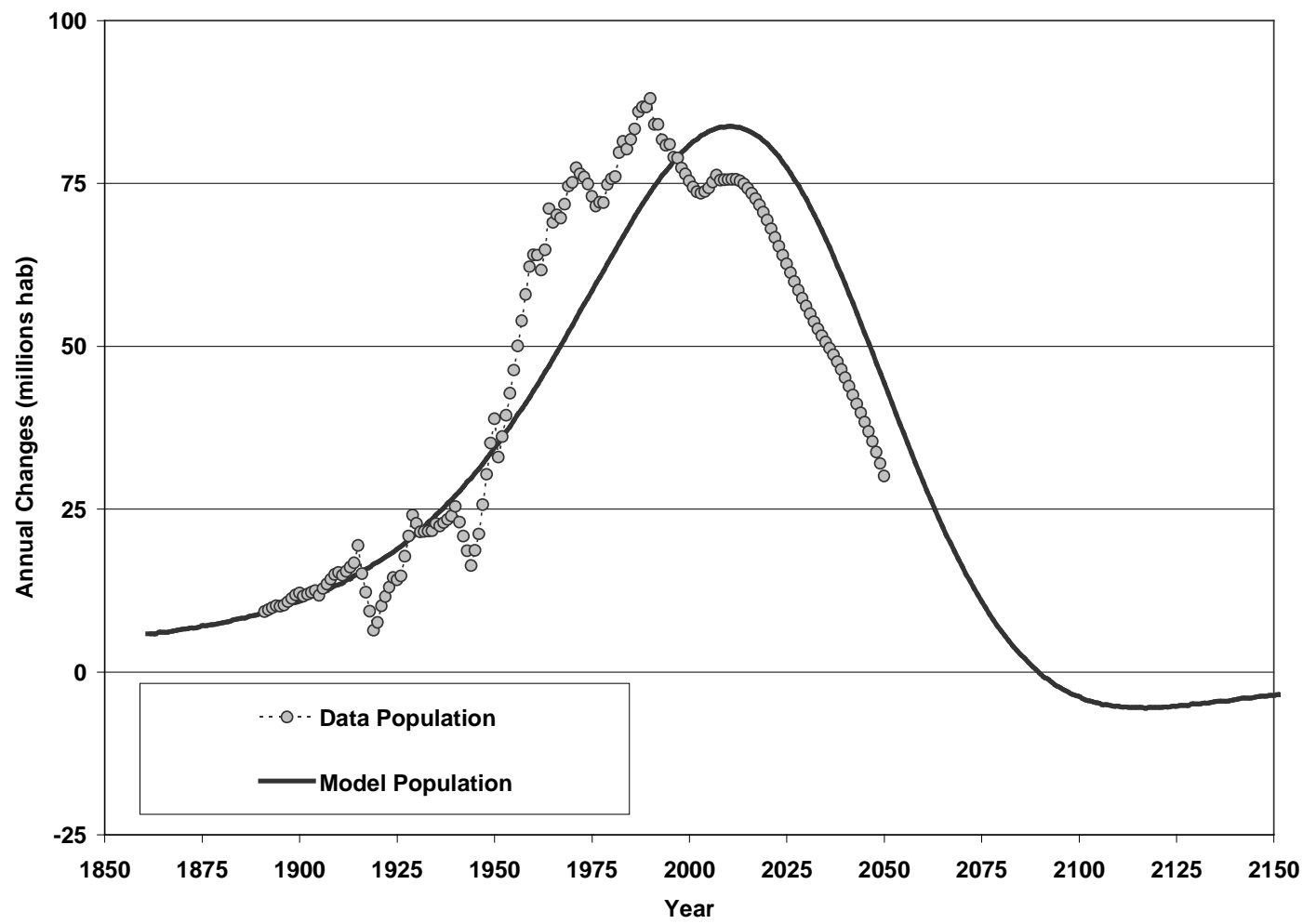

Figure 3. Comparison Model and Data for annual gross domestic product changes

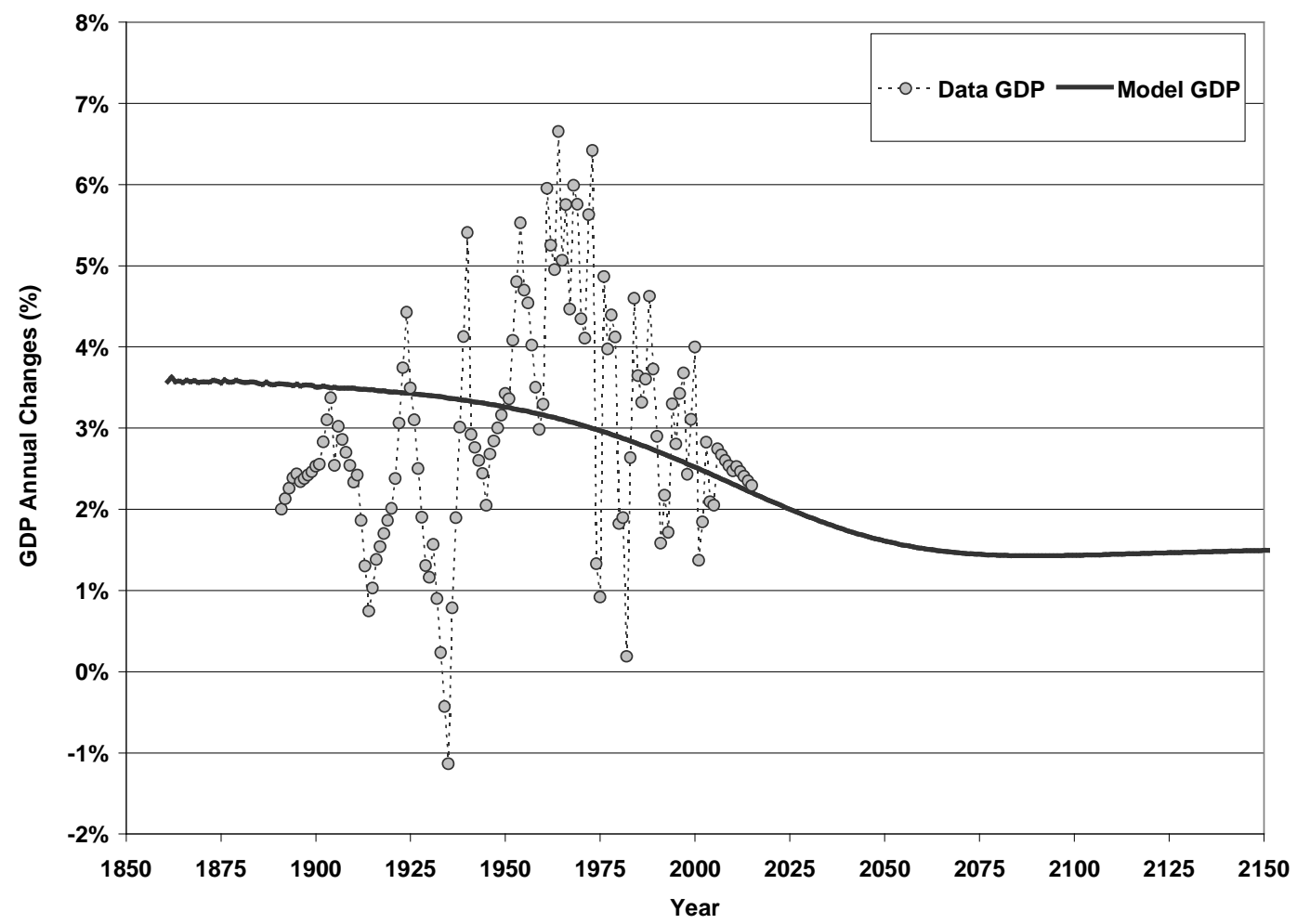




\section{Figure 4. Comparison Model and Data for GDP per capita}

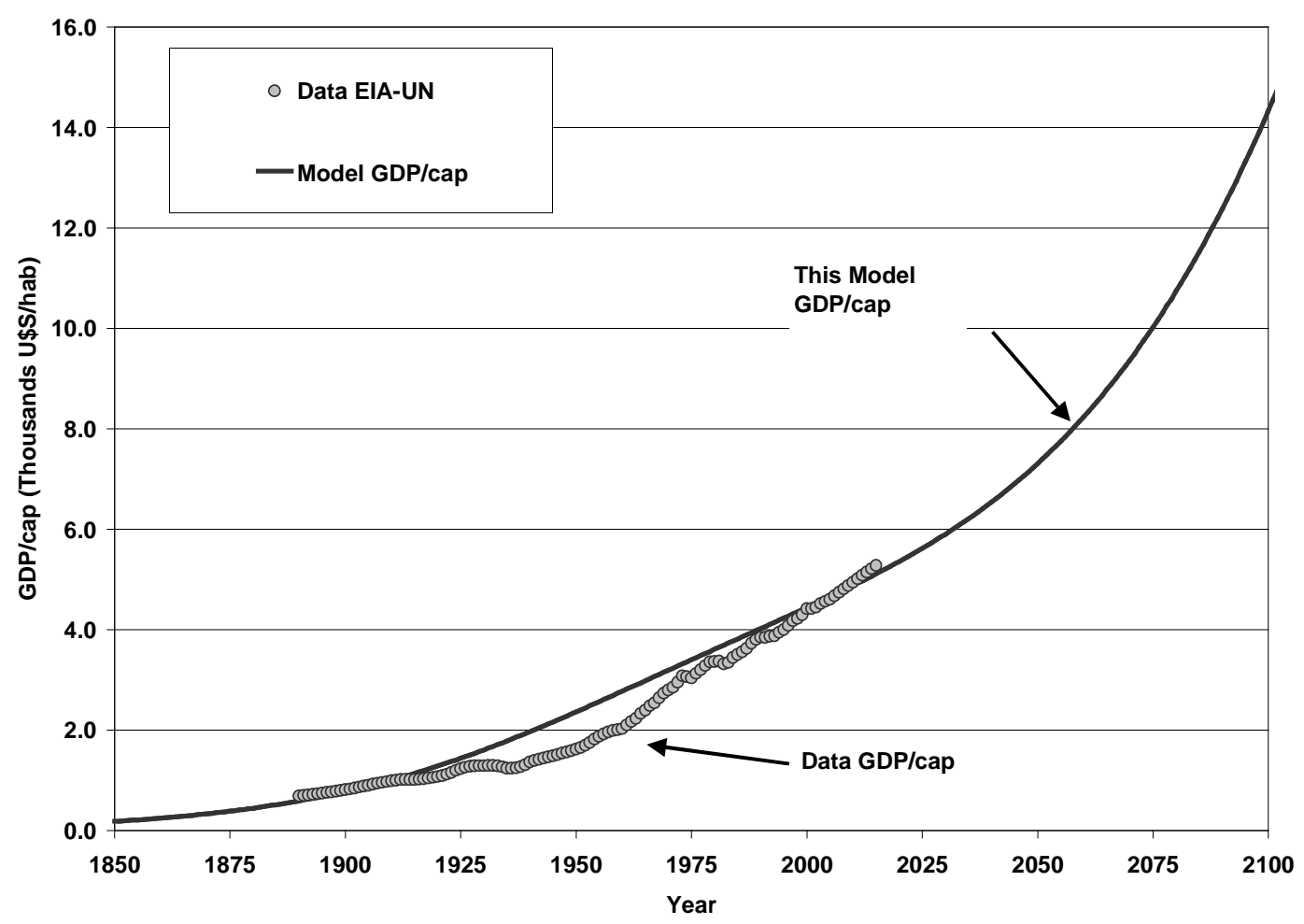

According to the proposed coefficients, the population will have a slow growth of about $0.3 \%$ per year (typical value for population growth prior to 1900), and it is boosted through the per capita growth rate increase present in the functional response $\alpha_{3} f$. But the same GDP growth will limit the population growth expressed by negative sign of $\alpha_{2}$. On the other side, the mean growth of GDP at a high rate of $3.1 \%$ is controlled by the population growth $\beta_{2}$. The function $f$ is then used as a proxy function to represent the technological and cultural changes. Since $g$ and $p$ are coupled, the function could also be applied to $g$ and obtain similar results. Figure 2 and Figure 3 show slow changes at the beginning of the transition phase, then reaches a maximum in years 1960-1970, followed by a steady decline, tending to a new stabilization phase by about 2070-2080 of about 10,000 Millions inhabitant. According to the proposed coefficients presented in Figure 3, the GDP changes tend to stabilize at a 1.5 $\%$ increase rate for a steady population. By increasing the absolute value of coefficient $\alpha_{2}$, the GDP rates will tend to diminish leveling the values of the GDP.

The rationale for this process is suggested by the following argument. According to current estimations, before 1900, both economic and population growth were small, approximately $1.3-2.0 \%$ for $g$ and $0.6-0.8 \%$ annual increases for $p$, which was the result of high mortality and high birth rates. Important theoretical and technological changes were 
introduced during the last half of the XIX Century and beginning of the XX Century, such as implementation of the vapor machines in industry and transportation, new vehicles (cars and first airplanes) advances in theoretical physics, advances in medicine (penicillin and antibiotics), the use of petroleum as main fuel, and so on. These advances in technology and knowledge boosted economic growth, reduced mortality rates and increased life expectancy, increasing the population, which began its transition from a labor-intensive agro-rural economy to a more urban industrial one. But the effect of the two World Wars, the Cold War, the oil crisis of the 70's, etc., produced a profound cultural and economic crisis, which stopped or slowed down both the economy and the birth rates. This effect was reinforced by the introduction of computation and automation, which reduced the need for manual activities, replacing human labor activity for fewer but highly educated/trained personnel, leading to a steady decline both in $p$ and $g$ as shown in Figures 2 and 3. If this tendency continues, the model predicts a stabilization (or even a decline) level for $g$ and $p$ for the end of this century and beginning of the next one. But in the same way we had in the past an important boost due to knowledge accumulation, it is very possible, that at some point in the next decades a new excitation may boost again the economy leading to a new phase of population growth, but probably, first, the fossil fuel energy based economy should shift to a new form of energy availability.

The role of technological changes in population and economic growth has been presented in many economical studies (Schumpeter, 1934; Kremer, 1993; Kozulj, 2003). It is interesting to note that Schumpeter not only had emphasized the role of technological progress, but despite the increasing trends in population and economic growth shown in the late '30s, he had foreseen the decline in capitalist economic growth due to internal causes, specially the disintegration of the bourgeois family, which profoundly affect the demographic trends (described in Schumpeter, 1942).

These three "times" or phases in the demographic transition are also in agreement with the descriptions of a "Malthusian regime", a "Post-Malthusian" and "Modern Growth" as expressed by Galor and Weil, (2000): "In the Malthusian regime, population growth is positively related to the level of income per capita. Technological progress is slow and is proportional to population increase, so GDP per capita is constant. In the "Post-Malthusian" regime, the growth rates of technology and GDP are high. Population growth absorbs much of the growth of output, but income per capita does rise slowly. The economy endogenously undergoes a demographic transition in which the positive relationship is reversed". 


\section{Model and simulations for energy demand and carbon emissions}

\subsection{The model}

The identification and understanding of key driving forces leading to carbon emission into the atmosphere confronts the researcher to deal with socio-economic variables that lie far beyond the atmospheric sciences, such as population growth, gross domestic product, and energy consumption, among others. Despite the tremendous effort already developed to properly capture these matters in a model, there are still many open questions concerning the main ideas and interacting relations behind the anthropogenic greenhouse gases emissions. An important application to the model described in the above section is related to the estimation of energy consumption and global carbon emissions, which requires a better understanding of population dynamic and GDP growth. As stated above, during the early 1970s, Commoner (1971), and Ehrlich and Holdren (1972) proposed the IPAT identity as a first guess to analyze the driving forces of environmental change. The IPAT calculations establish that environmental impacts are the product or combination of three main driving forces: population, affluence (per capita consumption or production) and technology (impact per unit of consumption or production), then

$$
I=P \cdot A \cdot T
$$

In this identity, the impact $I$ (i.e. the carbon emissions), is accounted through the national inventories [tons of $\mathrm{CO}_{2}$ ], the population $P$ [hab] is well documented, the affluence $A$ is calculated as per capita gross domestic product [U $\$ \mathrm{~S} / \mathrm{hab}$ ], and $T$ (the effect of technology) is normally solved from this equation. $T$ also accounts for the efficiency of the emissions and may be measured as tons of $\mathrm{CO}_{2}$ per U\$S of the GDP. Other authors like Ogawa (1991), Nakicenovic et al, (1993), Watson et al, (1996), Gürer and Ban, (1997), O`Neill et al, (2000), Waggoner and Ausubel (2002), have proposed or used similar relations. This identity is sometimes also called Kaya identity (Kaya, 1990). In a general form, this identity can be seen as a composition of the following variables and indicators:

$$
\mathrm{CO}_{2} \text { Emissions }=\text { Population } \cdot[(\mathrm{GDP} / \text { Population }) \cdot(\text { Energy } / G D P)] \cdot\left(\mathrm{CO}_{2} / \text { Energy }\right)
$$


The bracket [.] in equation (6) represents the affluence $A$, and the most right parenthesis is the emissions' efficiency or $T$. Although the idea is simple and linear, the shortcoming of this identity is that it assumes that the variables are independent. So, a change in one of them will produce no effect on the other variable, which is not completely true, as we have seen in the precedent sections. However, it captures the main driver forces or state variables of the environmental impact of human activity. In the same line, York et al., (2003), and Dietz and Rosa (1997), have proposed a statistical modification to IPAT, called ImPACT and STIRPAT in the form of $I=a P^{b} A^{c} \varepsilon$, where $a, b$ and $c$ are country-dependent coefficients. The error factor $\varepsilon$, represents the uncertainties in estimating the technological factor.

The International Panel on Climate Change (IPCC) has developed several carbon emission scenarios (SRES) as input data for a global model of atmospheric circulation (IPCC, 2000). ${ }^{8}$ The objective of these models is to estimate the anthropogenic emissions of greenhouse gases and consequently the evaluation of possible mitigation and adaptation strategies.

In all the discussed models, key drivers such as population and economic output need to be used to estimate the energy consumption and the emission data. In this paper, we estimate the annual changes in energy consumption $e$ and carbon emission $c$ assuming a similar behaviour in the changes in GDP and population. Since $e$ and $c$ are strongly coupled to $g$ and $p$, we propose a similar set of differential equations as (3) to estimate the annual changes in both variables:

$$
\left\{\begin{array}{l}
\frac{d e}{d t}=\varepsilon_{1} e+\varepsilon_{2} p e \\
\frac{d c}{d t}=\sigma_{1} c+\sigma_{2} p c
\end{array}\right.
$$

where $\varepsilon_{1}$ is the rate of increase in energy consumption by a growing economy, in absence of any other limiting factor; $\varepsilon_{2}$ is the energy reduction by spare behaviors. Similar considerations can be said for changes in the carbon emissions, i.e, $\sigma_{l}$ is the increase in carbon emissions for a growing economy; $\sigma_{2}$ is the carbon emissions control or reduction through increasing

\footnotetext{
8 The IPCC is organized by the World Meteorological Organization (WMO) and the United Nations Environmental Program (UNEP) to advice the Conference of the Parties of the United Nations Framework Conventions on Climate Change (UNFCCC) to understand the complex relations and feedbacks concerning the climate change. Other international initiatives are organized in many well known programmes such as the
} 
environmental awareness in the population. It must be noted that to solve equation (7) it is necessary to run simultaneously equations (3), thus, obtaining four differential equations. This interrelation may be understood in the following way. A better efficiency induced by higher purchase possibilities and more investments in technology may produce on one side a reduction in consumption but also a may rise consumption due to higher purchase possibilities, as seen in developed countries.

\subsection{Simulation's results}

Figure 5 shows a representation of world primary energy consumption (EJ) and carbon emissions (GTn), using the proposed model compared to international agencies projections (from 1850 to 2004 measured or estimated values; from 2005 to 2150 projected values). The values for the coefficient of $p$ and $g$ used in Figure 5 are the same of Figure 1 through Figure 4. The coefficients of Equation (5) are: $E_{0}=0.90 \mathrm{EJ}, C_{0}=0.21 \mathrm{GTn} \mathrm{C}, \varepsilon_{1}=2.5 \%, \varepsilon_{2}=-$ $0.16 /\left(10^{9}\right.$ Hab. $) ; \sigma_{1}=2.5 \%, \sigma_{2}=-0.19 /\left(10^{9}\right.$ Hab. $)$

We have compared the model output to several IPCC-SRES projected scenarios (IPCC 2000, Pepper et al, 1992), for population (Figure 6), GDP (Figure 7), energy (Figure 8) and carbon emissions (Figure 9). As it can be appreciated, the model shows very good agreement for EIA projections up to year 2015, but seems to predict lower rates of GDP. By changing the proper coefficients $\left(\alpha_{2}, \alpha_{3} k_{1}\right.$, and $\beta_{2}$ it is possible to obtain GDP growth approaching to zero. The energy consumption and the carbon emissions of IPCC scenarios for year 2100 show a high degree of variances. In this model, we chose an intermediate value consistent with stabilization in lower rate for $g$ and $p .{ }^{9}$ As mentioned before, a better technology and efficiency may induce to energy reduction and also to decreasing carbon emission. Choosing other values of the control parameters will produce a shift in the maximum values, producing an early decay or a delay. Probably the carbon emissions will be reduced in the next decades, as more investments in cleaner technology are performed and fossil energy shifts towards other sources of energy generation followed by a growing environmental awareness.

\footnotetext{
International Geosphere-Biosphere Programme (IGBP), the International Human Dimensions Programme on Global Change (IHDP) and the Global Carbon Project (GCP).

${ }^{9}$ It must be noted, that by varying the control coefficients $\alpha, \beta, \varepsilon, \sigma$, it is possible to fit almost all the IPCC scenarios, i.e. more optimistic, conservative, or pessimistic, similar to the "storyline" proposed by the SRES scenarios.
} 
Figure 5. Comparison Model and Data for world primary energy consumption and carbon emissions

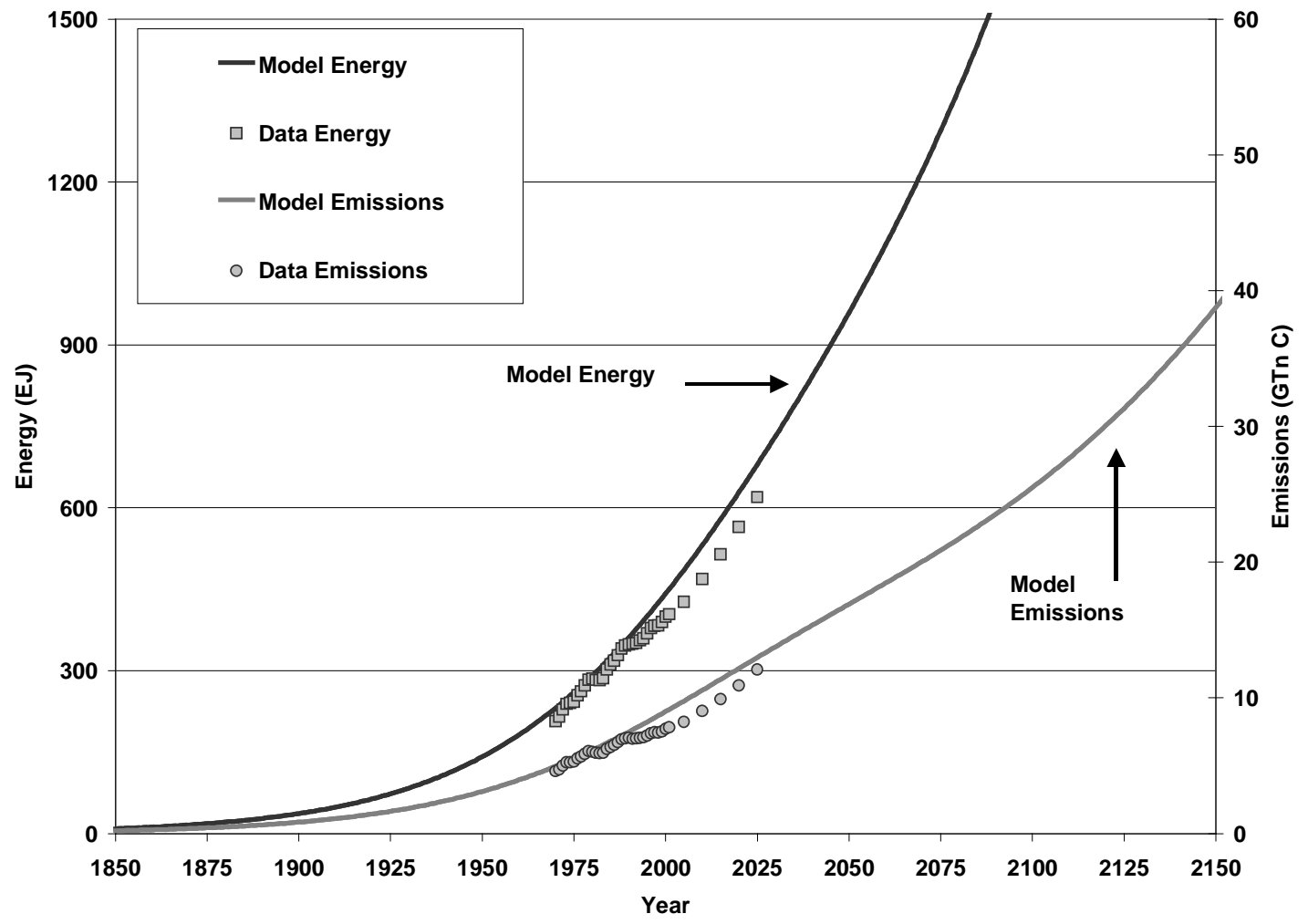

Figure 6. Results for Model population projections compared to IPCC SRES Models

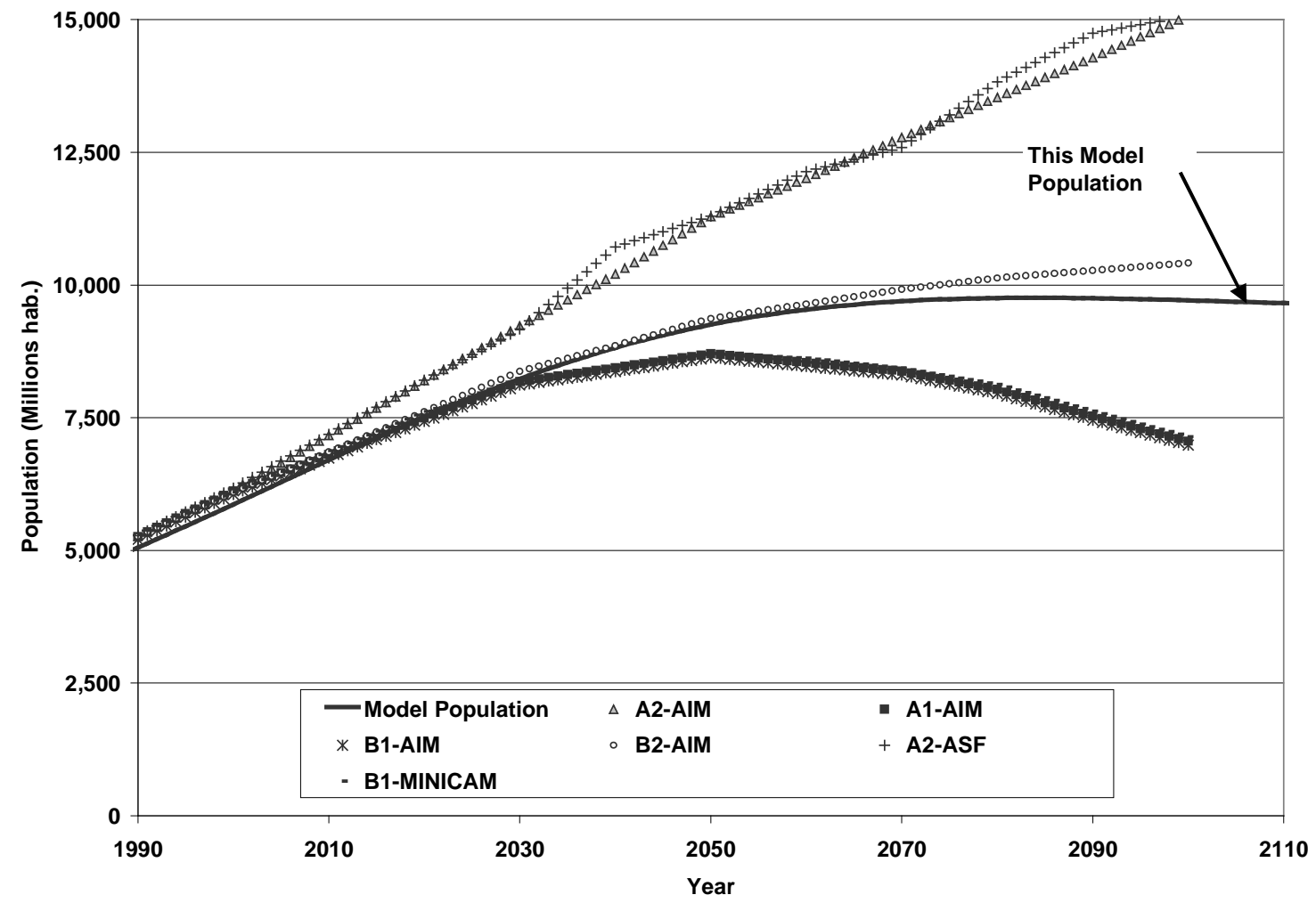


Figure 7. Results for Model world GDP projections compared to IPCC SRES Models

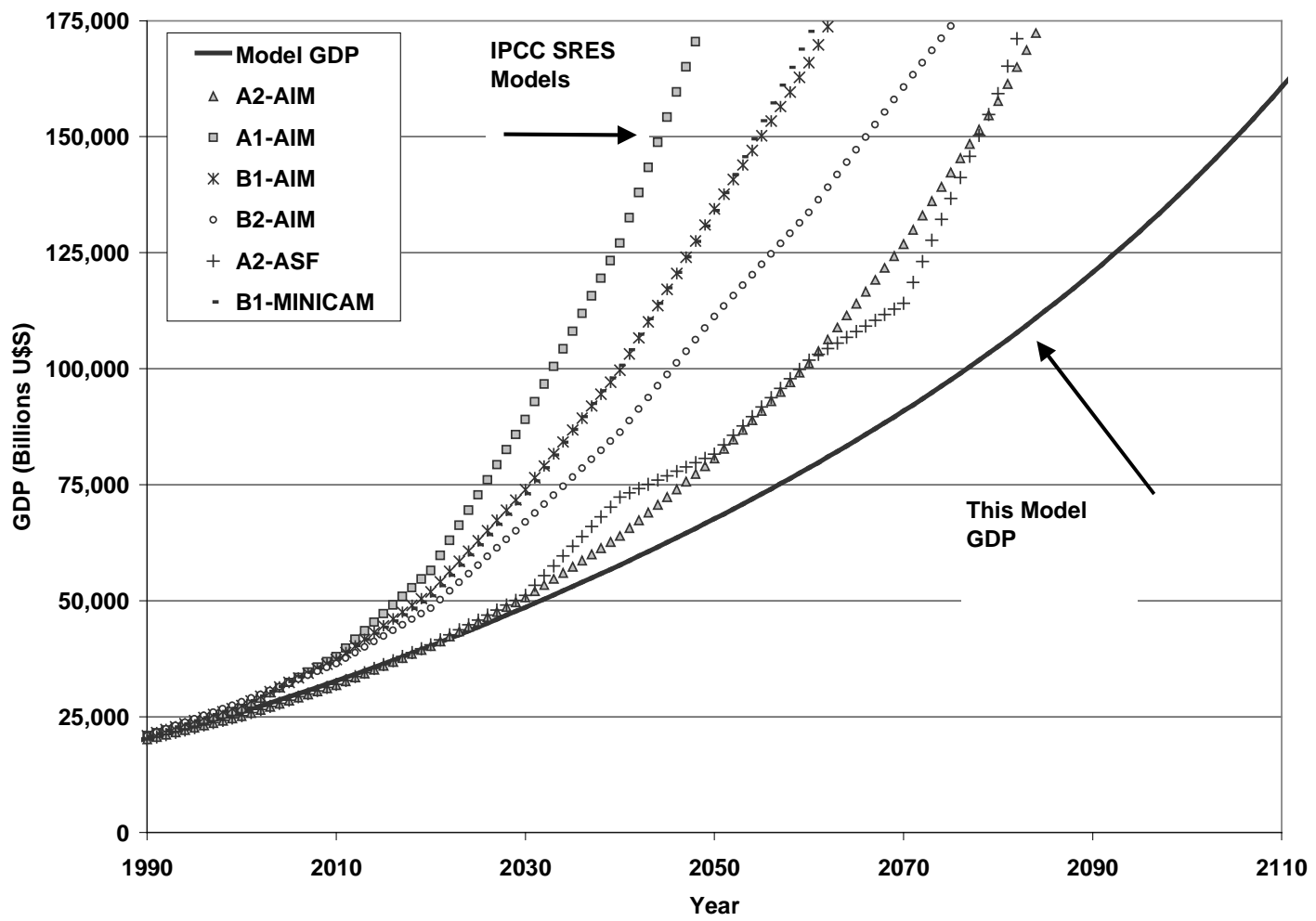

Figure 8. Results for Model world primary energy consumption compared to IPCC SRES Models

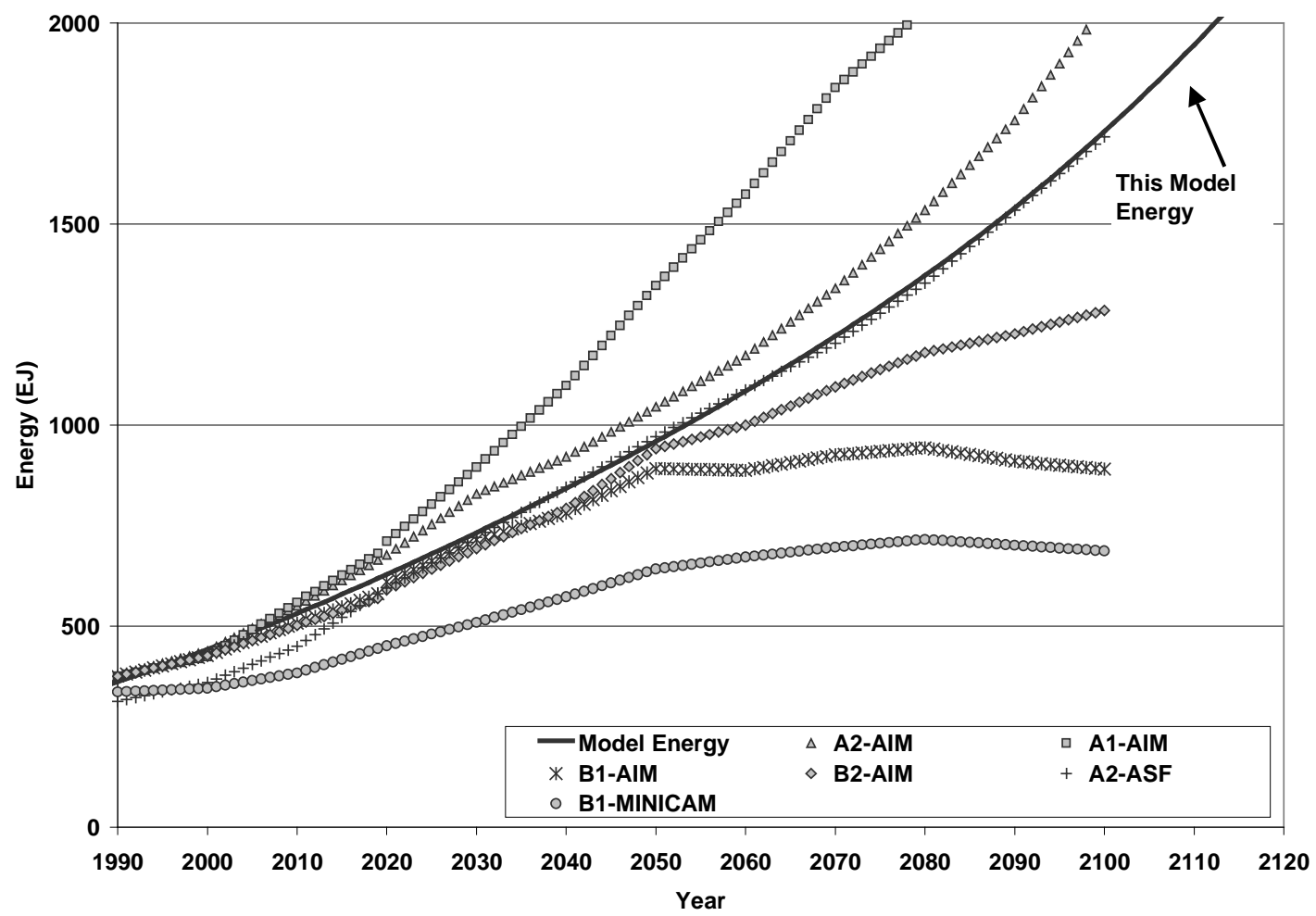


Figure 9. Results for Model world carbon emissions compared to IPCC SRES Models

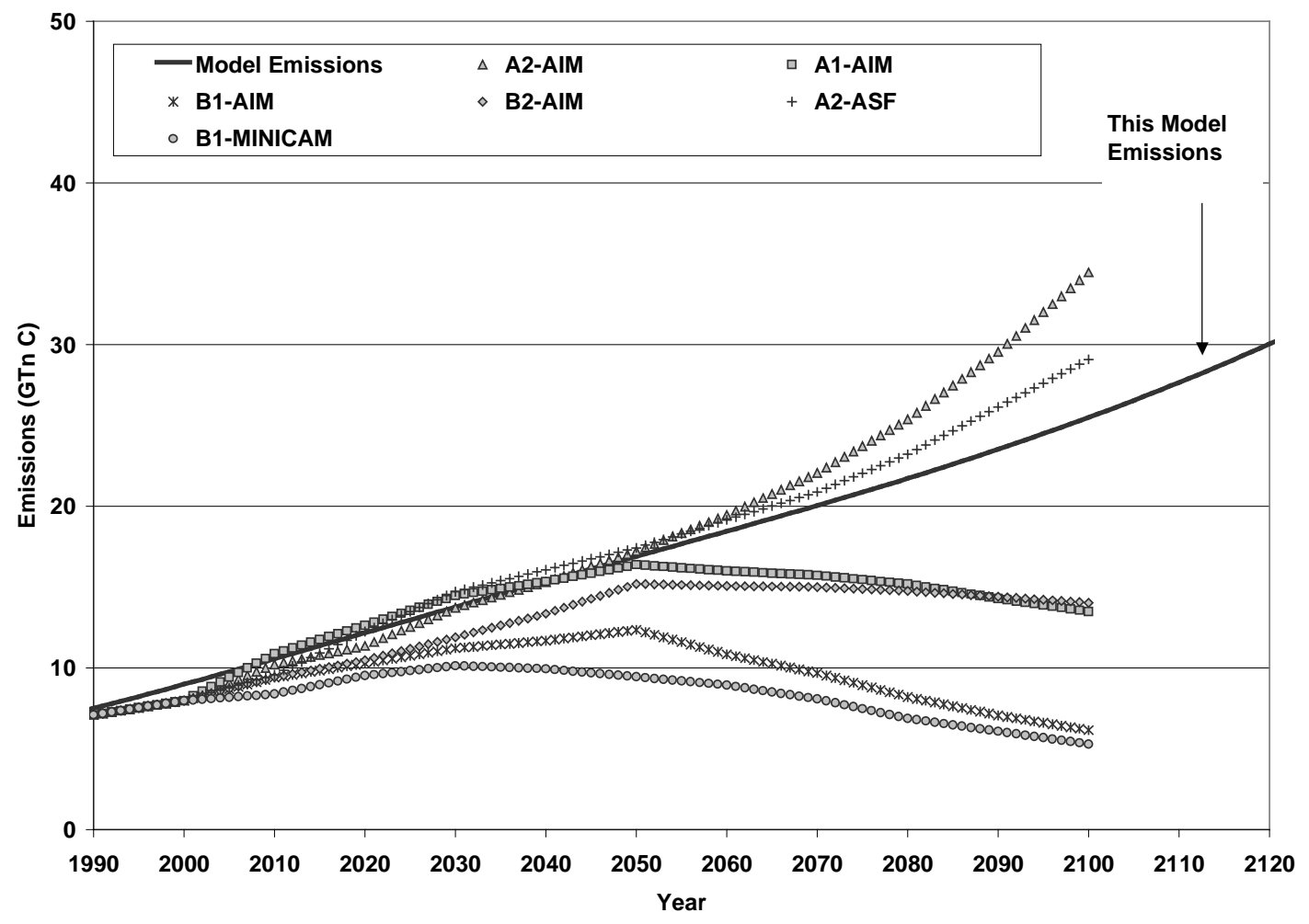

\section{Sensibility analysis}

To test the sensibility of the model to uncertainties in the parameter estimation, we performed a Monte Carlo simulation. The way to test different scenarios consists in varying the parameters $\alpha_{i}, \beta_{i}, \varepsilon_{i}$, and $\sigma_{i}$ randomly using a gaussian deviation. First, we select a set of values for the coefficients, which, for example matches the data and some reference model, i.e., the projections of the international statistics. Secondly, we added some random noise to the parameters, whose variances are increased proportionally with increasing time span: being $0 \%$ at 2000 up to $150 \%$ in year 2150 respect to the initial value. Finally, we compute the mean values, maximum and minimum values; and \pm 1 standard deviation, of population, gross domestic product, primary energy consumptions and carbon emissions for each run. This means that these parameters will change year after year in a random way with an increasing variance, which corresponds to an increasing uncertainty, as the projections moves forward from current knowledge. By running it several times, the simulation explores different possible combinations of parameter changes. As result, depending on the chosen variances it is possible to obtain all SRES IPCC Scenarios. 
It must be noted that the results shown in Figures 6 to 9 (for population, GDP, energy and emissions dynamics respectively) do not represent necessarily our best guess, since we choose as initial model the Reference projection of EIA. It can be further discussed which is the most acceptable set of values, but, as with the IPCC SRES, the selection will depend on the modelers' criteria based on available information. However, the present study does show that conceptually and mathematically the model describes the dynamic and interactions in population, economic output, energy consumption and carbon emissions. It also shows that it is able to capture a wide range of different scenarios with a set of simple coupled equations.

\section{Conclusions}

The on-going world demographic transition experienced since the beginning of the last century has mobilized demographers and social scientists to explain the causes of such transition, but also to foresee the impact such changes may have on the economy, labor, natural resources availability and emissions to the environment.

In this paper, we propose a set of ordinary differential equations for competing species to explain population dynamics, economic growth, energy consumption and carbon emissions. This system dynamic model is well known in the biological, ecological and environmental literature (as prey -predator or competing species) and has also been applied in other fields, like economics. These relations explain the changes in population of two species and are expressed in several forms, which include explicit functional responses, a carrying capacity or logistic growth functions. In this model, the inclusion of an additional function to the simplest LVR relations represents the influence that technological and cultural changes have on the population dynamic and economic growth.

The results of the model not only fits reasonably well the data or projections of international agencies (UN, EIA), but also explains in a simple mathematical way the transitional changes in population or economy. Additionally, we have applied the above model to estimate world energy demand and carbon emissions to the atmosphere, by adding two extra differential equations to those representing the population and economy annual changes. The model calculations were compared to several agencies projections (IPCC, EIA), leading to comparable results, and obtaining similar scenarios outputs. Thus, the value of the

present model is not only the ability to reproduce in a wide range the current projections, but also to capture conceptually in a simple mathematically formalism the present transitional trends in population, economy, energy-demand and carbon emissions. 
Finally, it is important to note that world mean values hide big differences among regions and group of countries. However, the application of the model on a group of countries or regions, i.e. North America, Europe, Asia, Latin America, give also similar good fits as presented for the world mean values. Next studies will be oriented towards the consideration of regional geographical distributed information of GDP, population, energy consumption, and carbon emissions. Some studies performed on urban centers based on a geographical information system (GIS) (Puliafito, 2002, 2004, 2006) show similar behavior, and the set of proposed equations seems to fit also very well. In further research, we will explore the adaptability of these equations for several urban centers and dense populated areas.

\section{References}

Abrams, P. and Holt, R., 2002. The Impact of Consumer-Resource Cycles on the Coexistence of Competing Consumers, Theoretical Population Biology 62, pp. 281-295.

Alcamo, J. (Editors), 1994. IMAGE 2.0: Integrated Modeling of Global Climate Change. Dordrecht, The Netherlands: Kluwer Academic Publishers.

Armstrong, R. A., and McGehee, R., 1976, Coexistence of species competing for shared resources, Theoretical Population Biology, 9, pp. 317-328.

Ayres, R.,2004.: On the life cycle metaphor: where ecology and economics diverge, Ecological Economics, 48(2004) pp. 425-438.

Barro R. and Sala-I- Martin, X., 1998, Economic Growth, The MIT Press, Reprint edition.

Beisner, B.E., Ives, A.R. and Carpenter, S.R., 2003. The effects of an exotic fish invasion on the prey communities of two lakes. Journal of Animal Ecology, 72, pp. 331-342.

Biraben, Jean-Noel, 1980. An Essay Concerning Mankind's Evolution, Population, Selected Papers, December, table 2.

Blaine, T. and DeAngelis, D., 1997. The interaction of spatial scale and predator-prey functional response, Ecological Modelling, 95, pp. 319-328.

Capello, R., and Faggian, A., 2002. An economic-ecological model of urban growth and urban externalities: empirical evidence from Italy, Ecological Economics, 40, pp. 181198.

Carpenter, S.R., Cottingham, K.L. and Stow, C.A.1994. Fitting predator -prey models to times series with observation errors. Ecology, 75, pp. 1254-1264.

Casagrandi, R. and Rinaldi, S. 2002. A theoretical approach to tourism sustainability. Conservation Ecology, 6(1), 13.

Cass, D., 1965. Optimum Growth in an Aggregative Model of Capital Accumulation, Review of Economic Studies, 32, pp. 233-240.

Commoner, B., Corr, M. and Stamler, P.J. 1971. The causes of pollution, Environment, Vol. 13(3), pp. 2 -19.

Dendrinos, D.S. and Mullally, H. 1981. Evolutionary patterns of urban populations. Geographical Analysis, 13(4), pp. 328-344.

Dendrinos, D.S., and Mullally, H. 1983. Optimum control in nonlinear ecological dynamics of metropolitan areas. Environment and Planning, A 15, pp. 543-550.

Dietz, T. and Rosa, E. 1997. Effects of population and affluence on CO2 emissions, Proc. Natl. Acad. Sci. USA, Ecology, Vol. 94, pp. 175-179. 
Durand, J.D., 1974. Historical Estimates of World Population: An Evaluation. University of Pennsylvania, Population Center, Analytical and Technical Reports, No. 10.

Durand, J.D., 1977. Historical estimates of world population. Population and Development Review, 3(3): 253-296.

Ehrlich, P. and Holdren, P., 1971. Impact of Population Growth. Science, 171: 1212-17.

EIA, 2005. Energy Information Administration: International Energy Outlook 2005, www.eia.doe.gov/oiaf/ieo/index.html.

Fenlon, J. and Faddy, M., 2006. Modelling predation in functional response, Ecological Modelling, 198,pp. 154-162.

Forrester, J., 1961. Industrial Dynamics, Waltmhan M.A., Pegasus Communications.

Forrester, J., 1971. World Dynamics, Waltmhan M.A., Pegasus Communications.

Galor, O. and Weil, D., 2000. Population, Technology, and Growth: From Malthusian Stagnation to the Demographic Transition and Beyond, American Economic Review, September, 90(4), pp. 806-828.

Goodwin, R.M., 1969. A growth cycle. In: Feinstein, C.H. (Ed.), Socialism, Capitalism and Economic Growth. Cambridge University Press, Cambridge.

Gürer, N. and Ban, J.,1997. Factors affecting energy-related $\mathrm{CO}_{2}$ emissions: past levels and present trends. OPEC Review, XXI(4), pp. 309-350.

Harrison, P., 1993. The Third Revolution. Penguin, London.

Harrison, P. and Pearce, F., 2000. AAAS Atlas of Population and Environment. University of California Press, Los Angeles.

Hernández, J. and León C.,2006. "The interactions between natural and physical capitals in the tourist lifecycle model", Ecological Economics in press.

Holling, C. S. (1959):. The components of predation as revealed by a study of small mammal predation of the European pine sawfly, Can. Ent., 91, pp. 293-320.

Holtz-Eakin D. and Selden, T. M., 1995. Stoking the Fires? $\mathrm{CO}_{2}$ Emissions and Economic Growth, Journal of Public Economics, May, v. 57, issue. 1, pp. 85-101.

IMF, 2004. International Monetary Fund: World Economic and Financial Survey, World Economic Outlook, The Global Demographic Transition, September 2004. http://www.imf.org/external/index.htm.

IPCC, 2000. International Panel on Climate Change: Special Report on Emissions Scenarios. Nebojsa Nakicenovic and Rob Swart (Editors.), Cambridge University Press, UK.

Janssen, A., van Gool, E., Lingeman, R., Jacas, J. and van de Klashorst, G., 1997. Metapopulation dynamics of a persisting predator-prey system in the laboratory: time series analysis. Experimental \& Applied Acarology, 21, pp. 415-430.

Johansen, A. and Sornette, D., 2001. Finite-time singularity in the dynamics of the world population, economic and financial indices, Physica, A 294, pp. 465-502.

Jost, C. and Arditi, R., 2000. Identifying predator-prey processes from time-series. Theoretical Population Biology, 57, pp. 325-337.

Jost, C. and Ellner, S.P., 2000. Testing for predator dependence in predator-prey dynamics: a non-parametric approach. Proceedings of the Royal Society of London, B 267, pp. 1611-1620.

Kaya, Y., 1990. Impact of Carbon Dioxide Emission Control on GNP Growth: Interpretation of Proposed Scenarios. Paper presented to the IPCC Energy and Industry Subgroup, Response Strategies Working Group, Paris.

Klein Goldewijk, K., 2005. Three centuries of global population growth: A spatial referenced population density database for 1700 - 2000, Population and Environment, 26(5): 343367. 
Koopmans T. C., 1965. On the Concept of Optimal Economic Growth, in The Econometric Approach to Development Planning. Amsterdam: North-Holland; and Chicago: Rand McNally.

Kozulj, R., 2003. People, cities, growth and technological change. From the golden age to globalization, Technological Forecasting \& Social Change, 70:199-230.

Kremer, M., 1993. Population growth and technological change one million b. C. to 1990, Quarterly Journal of Economics, 108: 681-716.

Krutilla, K. and Reveuny, R., 2006. The systems dynamics of endogenous population growth in a renewable resource-based growth model, Ecological Economics, 56, pp. 256267.

Kuznets, S., 1965. Economic Growth and Income Inequality, in Economic Growth and Structure: Selected Essays, W. W. Norton, New York.

Lantz, V. and Feng, Q., 2006. Assessing income, population, and technology impacts on CO2 emissions in Canada: Where's the EKC?, Ecological Economics, 57: 229-238.

Lotka, A. J., 1925. Elements of physical biology. Baltimore: Williams \& Wilkins Co.

Lucas, R., 1988. On the Mechanics of Economic Development, Journal of Monetary Economics, 22:1, pp. 3-42.

MacArthur, R. H., 1970. Species packing and competitive equilibria for many species, Theor. Popul. Biol., 1, pp. 1-11.

Maddison, A., 1995. Monitoring the world economy 1820 - 1992, OECD, Paris.

Malthus, T.,1798. An Essay on the Principle of Population.

Marchetti C., Meyer, P. and Ausubel, J., 1996. Human Population Dynamics Revisited with the Logistic Model: How Much Can Be Modeled and Predicted?, Technological Forecasting and Social Change, 52, pp. 1-30.

McEvedy, C. and Jones, R., 1978. Atlas of World Population History, Middlesex, England: Viking Penguin. pp. 342-351. January 1978, ISBN: 0871964023.

Nakicenovic N., A. Grübler, A. Inaba, S. Messner, S. Nilson, Nishimura Y., Rogner H-H., Schäfer A., Schrattenholzer L., Strubegger M., Swisher J., Victor D. and D. Wilson, 1993. Long-term strategies for mitigating global warming. Energy, 18(5), pp. 401-609.

Neumayer E., 2002. Can natural factors explain any cross-country differences in carbon dioxide emissions, Energy Policy, 30: 7-12.

Nordhaus, W.D., 1992. The "DICE" Model: Background and Structure of a Dynamic Integrated Climate-Economy Model of the Economics of Global Warming No. Discussion Paper No. 1009. Cowles Foundation for Research in Economics at Yale University.

Ogawa, Y., 1991. Economic activity and greenhouse effect. The Energy Journal, 12(1), pp. 23-34.

O'Neill, B.C., F.L. MacKellar and Lutz, W., 2000. Population and Climate Change. Cambridge University Press, Cambridge.

Panatoyou, T., 2000. Economic Growth and the Environment, Working paper No. 56, Center for International Development at Harvard University.

Pepper, W.J., J. Leggett, R. Swart, J. Wasson, J. Edmonds, and Mintzer, I., 1992. Emissions Scenarios for the IPCC. An Update: Assumptions, Methodology, and Results. Support Document for Chapter A3. In Climate Change 1992: Supplementary Report to the IPCC Scientific Assessment. J.T. Houghton, B.A. Callandar and S.K. Varney (eds.), Cambridge University Press, Cambridge.

Press, W.H., Teukolsky, S.A., Vetterling, W.T. and Flannery, B.P., 1999. Numerical Recipes in Fortran, 77, 2nd edition. Cambridge University Press, Cambridge.

Puliafito, J.L., 2002. Urban evolution modelling: a macro quantum approach for Great Mendoza, in Design and Nature: Comparing Design in Nature with Science and 
Engineering. C. A. Brebbia and L J. Sucharov, Wessex Institute of Technology, United Kingdom and P. Pascolo, Universita degli di Udine, Italy (eds)ISBN: 1-85312901-1 Series: Design and Nature, Vol 3.

Puliafito, J.L., 2004. La evolución urbana desde el punto de vista de un modelo espaciotemporal: caso Gran Mendoza, in Mecánica Computacional Vol. XXIII - G.Buscaglia, E.Dari, O.Zamonsky (Editors.), pp. 2701-2720. Asociación Argentina de Mecánica Computacional (AMCA) Bariloche, Argentina.

Puliafito, J.L., 2006. A transport model for the evolution of urban systems, Applied Mathematical Modelling, in press, doi:10.1016/j.apm.2006.09.005.

Ramos-Jiliberto, R., 2005 Resource consumer models and the biomass conversion principle, Environmental Modelling \& Software, 20, pp. 85-91.

Ramsey, F., 1928. A Mathematical Theory of Saving, Economic Journal, Vol. 38, December, pp. 543-559.

Raskin, P.D., 1995. Methods for estimating the population contribution to environmental change, Ecological Economics, 15, pp. 225233.

Romer, P., 1986. Increasing Returns and Long-Run Growth, Journal of Political Economy, 94:5, pp. 1002-1037.

Romer, P., 1994. The Origins of Endogenous Growth, The Journal of Economic Perspectives, 8:1, pp. 3-22.

Samuelson, P.A., 1971. Generalized predator-prey oscillations in ecological and economic equilibrium. Proc.Natl.Acad. Sci. U.S.A., 68, pp. 980-983.

Schmalensee R., Stoker, T.M. and Judson, R.A., 1998. World Carbon Dioxide Emissions: 1950-2050, The Review of Economics and Statistics, February, v. 80, iss. 1, pp. 15-27.

Schumpeter, J., 1934. The Theory of Economic Development, Harvard University Press, Cambridge, MA,.

Schumpeter, J., 1942 Capitalism, Socialism and Democracy. New York: Harper \& Row, 1942, $381 \mathrm{pp}$.

Seidl, I.. and Tisdell, C., 1999. Carrying capacity reconsidered: from Malthus' population theory to cultural carrying capacity, Ecological Economics, 31, pp. 395-408.

Seppelt, R. and Richter, O., 2005.: "It was an artefact not the result": A note on systems dynamic model development tools, Environmental Modelling \& Software, 20, pp. $1543-1548$.

Shertzer, K.W., Ellner, S.P., Fussman, G.F. and Hairston, N.G., 2002. Predator-prey cycles in an aquatic microcosm: testing hypotheses of mechanism. Journal of Animal Ecology, 71, pp. 802-815.

Shi, A., 2003. The impact of population pressure on global carbon dioxide emissions: 19751996: evidence from pooled cross-country data, Ecological Economics, 44: 29-42.

Solow, R. M., 1956. A Contribution to the Theory of Economic Growth, Quarterly Journal of Economics, 70, pp. 65-94.

Song, X. and Xiang, Z., 2006. The prey-dependent consumption two-prey one-predator models with stage structure for the predator and impulsive effects, Journal of Theoretical Biology, 242 , pp. 683-698.

Stern, P.C., Young, O.R. and Druckman, D. (Editors.), 1992. Global Environmental Change: Understanding the Human Dimensions.National Academy Press, Washington, D.C.

United Nations, 2004. World Population Prospects: The 2004 Revision: http://www.un.org/esa/population/unpop.htm.

United Nations, 1973. The Determinants and Consequences of Population Trends, Population Studies, No. 50.

United Nations, 1999. The World at Six Billion, http://www.un.org/esa/population/publications/sixbillion/sixbilpart1.pdf. 
U.S. Census Bureau, 2006. Total Midyear Population for the World: 1950-2050. http://www.census.gov/ipc/www/worldpop.html.

Volterra, V., 1926. Variazioni e fluttuazioni del numero d'individui in specie animali conviventi. Mem. R. Accad. Naz. dei Lincei. Ser. VI, vol. 2.

Waggoner P.E. and Ausubel, J.H., 2002. A framework for sustainability science: A renovated IPAT identity, Proceedings of the National Academy of Sciences, 99(12):7860-7865.

Wang, K., Shallcross, D., Hadjinicolaou, P. and Giannakopoulos, C., 2002. An efficient chemical systems modelling approach, Environmental Modelling \& Software, 17, pp. 731-745.

Watson, R., M.C. Zinyowera, and Moss, R. (Editors.), 1996. Climate Change 1995. Impacts, Adaptations and Mitigation of Climate Change: Scientific Analyses. Contribution of Working Group II to the Second Assessment Report of the Intergovernmental Panel on Climate Change, Cambridge University Press, Cambridge, $861 \mathrm{pp}$.

Woodwell, J., 1998. A simulation model to illustrate feedbacks among resource consumption, production, and factors of production in ecological-economic systems, Ecological Modelling, 112, pp. 227-247.

World Bank, 2005. World Development Indicators, Washington D.C, http://www.worldbank.org/data/wdi2000/index.htm.

York, R., Rosa, E.A. and Dietz, T., 2002. Bridging environmental science with environmental policy: plasticity of population, affluence, and technology. Social Science Quarterly, 83(1), 18-34.

York, R., Rosa, E.A. and Dietz, T., 2003. Methods STIRPAT, IPAT and ImPACT: analytic tools for unpacking the driving forces of environmental impacts, Ecological Economics, Vol. 46, pp. 351-365. 